\title{
Enduring Resistance to Extinction of Cocaine-Seeking Behavior Induced by Drug-Related Cues
}

Friedbert Weiss, Ph.D., Rémi Martin-Fardon, Ph.D., Roberto Ciccocioppo, Ph.D., Tony M. Kerr, B.S., Diana L. Smith, M.A., and Osnat Ben-Shahar, Ph.D.

The conditioning of cocaine's pharmacological actions with environmental stimuli is thought to be a critical factor in long-lasting relapse risk associated with cocaine addiction. To study the significance of environmental stimuli in enduring vulnerability to relapse, the resistance to extinction of drug-seeking behavior elicited by a cocainerelated stimulus was examined. Male Wistar rats were trained to associate discriminative stimuli $\left(S^{D}\right)$ with the availability of intravenous cocaine $\left(S^{+}\right)$vs. the availability of non-rewarding $\left(S^{-}\right)$saline solution, and then placed on extinction conditions during which intravenous solutions and $S^{D}$ were withheld. The rats were then presented with the $S^{+}$or $S^{-}$alone in 60-min reinstatement sessions conducted at 3-day intervals. To examine the long-term persistence of the motivating effects of the cocaine $S^{+}, a$ subgroup of rats was re-tested following an additional three months of abstinence during which time the rats remained confined to their home cages. Re-exposure to the cocaine $S^{+}$ selectively elicited robust responding at the previously active lever. The efficacy and selectivity of this stimulus to elicit responding remained unaltered throughout a 34-day phase of repeated testing as well as following the additional extended abstinence period. In pharmacological tests, conducted in a separate group of rats, the dopamine (DA) $D_{1}$ antagonist $S C H 39166(10 \mu \mathrm{g} / \mathrm{kg})$, the $D_{2 / 3}$ antagonist nafadotride $(1 \mathrm{mg} / \mathrm{kg})$, and the $\mathrm{D}_{2 / 3}$ agonist PD $128907(0.3$ $\mathrm{mg} / \mathrm{kg}$ ) suppressed the cue-induced response reinstatement while the $D_{1}$ agonist SKF $81297(1.0 \mathrm{mg} / \mathrm{kg})$ produced a variable behavioral profile attenuating cue-induced responding in some rats while exacerbating this behavior in others. The results suggest that the motivating effects of cocaine-related stimuli are highly resistant to extinction. The undiminished efficacy of the cocaine $S^{+}$to induce drug-seeking behavior both with repeated testing and following long-term abstinence parallels the long-lasting nature of conditioned cue reactivity and cue-induced cocaine craving in humans, and confirms a significant role of learning factors in long-lasting vulnerability to relapse associated with cocaine addiction. Finally, the results support a role of DA neurotransmission in cue-induced cocaine-seeking behavior.

[Neuropsychopharmacology 25:361-372, 2001] (C) 2001 American College of Neuropsychopharmacology. Published by Elsevier Science Inc. All rights reserved.
From the Department of Neuropharmacology, The Scripps Research Institute, La Jolla, CA 92037 (FW, RM-F, RC, TMK, DLS), and Department of Psychology, University of California, Santa Barbara, CA 93106 (OB-S)

Address correspondence to: Friedbert Weiss, Ph.D., Department of Neuropharmacology, CVN-15 The Scripps Research Institute, 10550 North Torrey Pines Road, La Jolla, CA 92037; Tel.: 858-7847068; Fax: 858-784-7393; email: bweiss@scripps.edu

Received May 17, 2000; revised November 3, 2000; accepted January 19, 2001.

Online publication: 1/30/01 at www.acnp.org/citations/Npp 01300174.
KEY WORDS: Reinstatement; Relapse, dopamine; SCH 39166; SKF 81297; PD 128907; Discriminative stimulus, Conditioned stimulus; Occasion setter

Cocaine addiction is a chronic relapsing disorder (Leshner 1997; O'Brien et al. 1998; O'Brien and McLellan 1996). Relapse prevention has therefore emerged as a central issue in treatment and medications development efforts (Carroll et al. 1991; DeLong 1994; O'Brien 
and McLellan 1996). A wealth of clinical studies point towards drug-related stimuli or events as a critical factor in the long-lasting compulsion to abuse drugs. This literature suggests that environmental stimuli repeatedly paired with the subjective actions of cocaine throughout an individual's history of drug abuse can produce intense drug craving (Childress et al. 1988; Ehrman et al. 1992; Kilgus and Pumariega 1994; Robbins et al. 1997; Satel et al. 1995; Wallace 1989) or elicit automatic behavioral responses (Miller and Gold 1994; Tiffany and Carter 1998) that may lead to relapse.

Consistent with a role of conditioning factors in the resumption of drug abuse habits, several studies in animals have demonstrated that drug-associated stimuli can elicit a transient recovery of extinguished responding at a lever previously associated with cocaine selfadministration (e.g., deWit and Stewart 1981; Fuchs et al. 1998). However, little information is available, to date, about the persistence of cue-induced drug-seeking behavior. In recent work that has begun to address this issue, appreciable cued recovery of cocaine-seeking behavior was observed when rats were presented with cocaine cues on two separate occasions spaced 20 days apart. Similarly, the efficacy of a cocaine cue to reinstate extinguished cocaine-seeking behavior was found to persist for up to eight days of intermittent testing (Weiss et al. 2000). The latter study revealed also that cocaine cues increase extracellular dopamine levels in the nucleus accumbens and amygdala. These findings indicate that the behavioral effects of cocaine-related environmental stimuli can show resistance to extinction, and that their motivating effects may involve activation of forebrain DA neurotransmission.

Considering the mounting evidence that learned responses to cocaine-related stimuli represents a significant factor in long-lasting relapse risk (see O'Brien et al. 1998 for review), better understanding of the environmental, behavioral, and neuropharmacological bases of this phenomenon will be of substantial clinical benefit. The purpose of the present study was to characterize the resistance to extinction of cocaine-seeking behavior induced by a cocaine-associated environmental stimulus in rats under conditions of frequent repeated exposure to the cocaine cue, as well as following an additional long-term abstinence period during which rats remained confined to their home cages. A second issuein view of the recently reported activation of DA release in the nucleus accumbens and amygdala by cocaine cues (Weiss et al. 2000) and human brain imaging data implicating activation of DA-rich forebrain regions in cocaine craving (Breiter et al. 1997; Childress et al. 1999; Garavan et al. 1998; Grant et al. 1996) —was to confirm a dopaminergic involvement in the response-reinstating actions of cocaine-related environmental stimuli by determining whether these effects are sensitive to pharmacological manipulation of DA transmission.

\section{MATERIALS AND METHODS}

\section{Animals}

Male Wistar rats (Beckman Laboratories, The Scripps Research Institute, La Jolla, CA) weighing 250-300 g at the beginning of the experiment were housed in groups of two or three, in a humidity and temperature $\left(22^{\circ} \mathrm{C}\right)$ controlled vivarium on a 12/12-hr light/dark cycle (lights off at 6:00 P.M.) with ad libitum access to food and water except during initial operant training for foodreinforced responding. Training and testing were conducted during the light phase of the light/dark cycle at the same time each day. All procedures were conducted in strict adherence to the National Institutes of Health Guide for the Care and Use of Laboratory Animals.

\section{Apparatus}

Rats were trained and tested in standard $29 \times 24 \times 19.5$ $\mathrm{cm}$ operant conditioning chambers located inside ventilated sound attenuating cubicles (BRS/LVE Inc., Laurel, MD) and modified for intravenous self-administration as previously described (Weiss et al. 2000). All chambers were equipped with two retractable levers, a white cue light above each lever, and a house light located at the top of the chamber's front panel. Auditory stimuli consisted of a $70 \mathrm{~dB}$ white noise produced by a white-noise generator (The Salk Institute, San Diego, CA) and presented via an $80-\mathrm{ohm}$ speaker located in the center of the chamber's front panel below the house light, or an intermittent "beeping" tone $(7 \mathrm{kHz}, 70 \mathrm{~dB})$, generated by a tone source (Sonalert, Model SC628, 6-28 VDC, Mallory, CO) also located in the center of the front panel just above the speaker. Intravenous infusions were administered by a syringe pump (Razel Scientific Instruments, Stamford, CT) located outside the sound attenuating boxes. Testing equipment and data collection were controlled by an IBM-compatible microcomputer.

\section{Drugs}

Cocaine hydrochloride (National Institute on Drug Abuse, Bethesda, MD) was dissolved in sterile physiological saline at a concentration of $0.25 \mathrm{mg} / 0.1 \mathrm{ml}$. Cocaine or saline was infused intravenously at a volume of $0.1 \mathrm{ml}$ over a 4 -sec period. The dopamine (DA) $\mathrm{D}_{1}$ antagonist SCH 39166 (Schering-Plough, Kenilworth, NJ) was dissolved in ethanol $(1 \mu \mathrm{g} / 1 \mu \mathrm{l})$, diluted with saline to a concentration of $30 \mu \mathrm{g} / \mathrm{ml}$ and injected subcutaneously (SC) 30 minutes before reinstatement session at a dose of $10 \mu \mathrm{g} / \mathrm{kg}$. The $\mathrm{D}_{1}$ agonist R(+)SKF 81297 (Research Biochemical International, Natick, MA) was dissolved in physiological saline at a concentration of $1 \mathrm{mg} /$ $\mathrm{ml}$ and injected at a dose of $1 \mathrm{mg} / \mathrm{kg} \mathrm{SC}$ ). Nafadotride, a $\mathrm{D}_{2} / \mathrm{D}_{3}$ receptor antagonist (provided by J.C. Schwartz, 
Unité de Neurobiologie et Pharmacologie, INSERM, Centre Paul Broca, Paris, France) was dissolved in physiological saline at a concentration of $1 \mathrm{mg} / \mathrm{ml}$ and injected at a dose of $1 \mathrm{mg} / \mathrm{kg} \mathrm{SC}$. The $\mathrm{D}_{2} / \mathrm{D}_{3}$ receptor agonist S(+)PD 128907 (Research Biochemicals International, Natick, MA) was dissolved in physiological saline at a concentration of $0.3 \mathrm{mg} / \mathrm{ml}$ and injected at a dose of $0.3 \mathrm{mg} / \mathrm{kg}$ SC. SKF 81297, nafadotride, and PD 128907 were administered 10 minutes before the beginning of reinstatement sessions.

\section{Operant Training for Food-Maintained Responding}

Rats were initially food restricted (15 grams/day; Purina rat chow) in order to establish lever-pressing behavior maintained by $45 \mathrm{mg}$ food pellets (Noyes Inc., Lancaster, NH). Food pellets were available in 1-hr daily sessions on a fixed ratio 1 (FR 1) time out (TO) 1 -sec schedule of reinforcement. Only the right lever was available and the TO period during which the lever remained inactive was signaled by illumination of the cue light above the lever. Once rats earned 100 pellets / session, the TO period was increased to 20 seconds in two additional sessions. Food then was made available ad libitum again.

\section{Jugular Catheter Implantation}

Rats were implanted with chronic silastic catheters in the right jugular vein under halothane $(1.0-1.5 \%)$ anesthesia as previously described (Caine et al. 1993). Catheter patency was maintained by flushing with sterile heparin/saline (33.3 USP units/ml) solution before and after self-administration sessions. Rats with compromised catheters were implanted with a new catheter in the left jugular vein or excluded from the experiment.

\section{Self-Administration Training and Conditioning Protocols}

The purpose of these procedures was to train rats to intravenously self-administer cocaine while simultaneously establishing reliable discriminative stimuli $\left(\mathrm{S}^{\mathrm{D}}\right)$ associated with cocaine availability vs. non-availability. Self-administration training began seven days after surgery. During the first three days of this phase, sessions were initiated by extension of both levers and simultaneous presentation of an intermittent "beeping" tone (1-sec duration presented at 1-sec intervals) that served as a discriminative stimulus $\left(\mathrm{S}^{+}\right)$for cocaine availability and remained present throughout the session. Cocaine was then made available for two hours on a FR 1 schedule of reinforcement. Only the right lever was active and, when depressed, resulted in an infusion of cocaine and 20 seconds illumination of the house light during which time the lever remained inactive to avoid acci- dental overdosing. Responses at the left lever were recorded but had no programmed consequences. Beginning on day 4, daily access to cocaine was changed from a single 2-hr session to two consecutive 1-hr sessions, separated by 30 minutes. Starting on day 6 , a third daily 1-hr session was added during which saline was substituted for the cocaine solution. This session was initiated by extension of both levers and illumination of the cue light above the right lever which served as a discriminative stimulus $\left(\mathrm{S}^{-}\right)$signaling non-reward (i.e., the availability of saline only) and remained present throughout the session. Each response at the active lever resulted in infusion of $0.1 \mathrm{ml}$ saline and 20 seconds presentation of a white noise TO stimulus during which time the lever was inactivated. Responses at the left, inactive lever were recorded but had no programmed consequences. The sequence of the three daily sessions (i.e., two cocaine and one saline sessions) was random. Rats were removed from the self-administration chambers for 30 minutes between two cocaine sessions, and for 40-60 minutes between cocaine followed by saline sessions. Training under these contingencies was continued until the rats developed stable responding for cocaine $( \pm 10 \%$ of mean responses over three consecutive days) and ceased responding during saline sessions.

\section{Extinction Phase}

Extinction sessions consisted of single daily 1-hr sessions, initiated by extension of both levers but without presentation of the discriminative stimuli. Responses at the previously active lever had no scheduled consequences except for activation of the syringe pump motor. Extinction sessions continued until animals reached a criterion of $<4$ lever presses per session at the previously active lever for three consecutive days.

\section{Reinstatement Phase}

Reinstatement tests began one day after each individual animal had reached the extinction criterion. These tests lasted one hour and were conducted once every third day for a total of 12 sessions under conditions identical to those during cocaine or saline self-administration, except that cocaine or saline were not available. Sessions were initiated by extension of both levers and presentation of either the cocaine $\mathrm{S}^{+}$or $\mathrm{S}^{-}$. The respective $S^{D}$ remained present until retraction of the levers at the end of each session. In both conditions, responses at the previously active lever were followed by activation of the syringe pump motor and a 20 -sec signaled TO period (i.e., illumination of the house light in the $\mathrm{S}^{+}$condition, and presentation of a white noise in the $\mathrm{S}^{-}$condition) during which time the levers remained inactive. 
To confirm the behavioral selectivity of the discriminative stimuli, the rats were tested in the presence of the $\mathrm{S}^{-}$on the first day of the reinstatement phase. The animals then were repeatedly tested for response-reinstating effects of the cocaine $\mathrm{S}^{+}$in nine consecutive sessions (i.e., reinstatement sessions $2-10$; days $4-28$ postextinction), each separated by 2 -day periods during which the rats remained in their home cages. To further verify the selectivity of the behavioral effects of the discriminative stimuli, rats were again tested in the presence of the $\mathrm{S}^{-}$during session 11 of the reinstatement phase (day 31 post-extinction), followed by a final test with the cocaine $\mathrm{S}^{+}$on day 34 post-extinction (reinstatement session 12). Rats of this group (Group I) also served as vehicle controls for drug tests conducted in a second group of rats (Group II, see below) and received injections of vehicle solutions before reinstatement sessions $3,5,7$, and 9 (i.e., days 7, 13, 19 and 25 post-extinction), corresponding to the days when pharmacological tests were conducted in Group II.

\section{Delayed Reinstatement Test}

Following completion of the repeated cue exposure test phase, eight rats of Group I were randomly selected to study the long-term persistence of the behavioral effects of the cocaine $\mathrm{S}^{+}$. These animals were confined to their home cages in the vivarium for 12-14 weeks (i.e., until approximately 17-19 weeks after their last exposure to cocaine) and then retested individually for their behavioral response to the $S^{D}$. The rats were randomly assigned to two groups, and tested once with either the cocaine $\mathrm{S}^{+}(\mathrm{N}=4)$ or $\mathrm{S}^{-}(\mathrm{N}=4)$ using the same procedures as above.

\section{Drug Tests}

To study whether the cue-induced response reinstatement is sensitive to pharmacological manipulation of dopamine receptors, a second group of rats (Group II, $\mathrm{N}=10$ ) was prepared. The experimental protocols for self-administration training, extinction, and reinstatement sessions was identical to that in Group I, except that no delayed reinstatement tests were conducted. The rats were treated with pharmacological agents (using the procedures and doses described in "Drugs") prior to reinstatement sessions 3, 5, 7, and 9 (days 7, 13, 19 and 25 post-extinction). The animals received neither drug nor vehicle treatments during the $\mathrm{S}^{+}$reinstatement sessions preceding and following each drug test (i.e., reinstatement sessions 2, 4, 6, 8, 10; days 4, 10, 16, 22,28 post-extinction). To control for order effects, the rats were tested with the different agents in random sequence across the four drug test days.

\section{Data Analysis}

Differences among responses during the Training, Extinction and Reinstatement Phases were analyzed by one-way within subjects ANOVA, followed by Newman-Keuls post-hoc tests to identify differences between experimental phases and responses in the presence of the $\mathrm{S}^{+}$vs. $\mathrm{S}^{-}$. Differences in behavioral performance between the Groups I and II during the three experimen-



Figure 1. Lever-press responses during self-administration training, extinction and reinstatement sessions at an active (A) and inactive (B) lever. Training Phase: Cocaine-reinforced $(\bigcirc / \bullet)$ and saline/nonreinforced $(\circ / \bullet)$ responses during the final three days of the self-administration phase in two groups of rats trained to associate discriminative stimuli with the availability of intravenous cocaine $\left(\mathrm{S}^{+}\right)$or saline $\left(\mathrm{S}^{-}\right)$. Rats of Group $\mathrm{I}(\mathrm{O} / \mathrm{\circ})$ were designated for tests of the resistance to extinction of cocaine-seeking behavior induced by the cocaine $\mathrm{S}^{+}$during the Reinstatement Phase. Rats of Group II $(\bullet / \bullet)$ were used to examine the effects of pharmacological agents on $\mathrm{S}^{+}$-induced responding during the Reinstatement Phase (see Figure 3). No differences were observed between the number of responses during the first and second daily hour of cocaine availability (see Methods) in either of the groups. The data were, therefore, collapsed across daily cocaine sessions. Extinction Phase: Extinction responses at criterion ( $<4$ responses/session over three consecutive days). The number of days required to reach the criterion was $15.3 \pm 3.9$ (Group I) and $21.6 \pm 2.0$ (Group II). Reinstatement Phase: Responses in the presence of the $\mathrm{S}^{+}$ and $\mathrm{S}^{-}$in Group I $(\bigcirc)$ and Group II $(\bigcirc)$. Exposure to the $\mathrm{S}^{+}$ elicited significant recovery of responding in the absence of further drug availability while responding in the presence of the $\mathrm{S}^{-}$remained at extinction levels. Data for Group II represent reinstatement tests prior to the beginning of the pharmacological tests shown in Figure 3 (Drug Treatments). For statistical comparisons see "Results." 
tal phases were analyzed by mixed-factorial ANOVAs, followed by Simple Effects analyses and/or Newman Keuls post-hoc tests. The effects of the pharmacological agents on reinstatement responses in Group II were compared to the number of responses in the vehicletreated animals of Group I tested at post-extinction days corresponding to the respective drug test days in Group II and analyzed by mixed-factorial ANOVA, followed by simple effects analysis.

\section{RESULTS}

\section{Resistance to Extinction}

Self-Administration Training and Conditioning Phase. All rats of Group I $(\mathrm{N}=8)$ rapidly developed stable cocaine self-administration. The mean $( \pm$ SEM $)$ number of days required to reach the training criterion was $10.25 \pm$ 1.0. No differences in the mean number of responses were observed during the final three days of the training phase $\left(\mathrm{F}_{2,14}=1.83 ; \mathrm{NS}\right)$ or between the first and second daily hour of cocaine availability $\left(\mathrm{F}_{1,7}=1.70\right.$; NS). The data of the two daily cocaine sessions were therefore pooled for all subsequent analyses. While there were no differences in the number of cocaine-reinforced responses between the two daily cocaine sessions, responding during cocaine availability differed significantly $\left(\mathrm{F}_{1,7}=129.09 ; p<.00001\right)$ from that during saline availability (Fig 1, left panel). Only minimal responding was observed at the inactive lever during both cocaine and saline sessions.
Extinction Phase. The mean $( \pm \mathrm{SEM})$ number of responses per session during the first three sessions of the extinction phase was $11.6 \pm 1.44$. The rats required on average $15.3 \pm 3.9$ sessions to reach the extinction criterions. Responding at the inactive lever was negligible throughout the extinction phase (Figure 1, center panel).

Reinstatement Phase. Responding at the active lever remained at extinction levels during testing in the presence of the non-reward $\mathrm{S}^{-}$on the first day of the reinstatement phase. In contrast, exposure to the $\mathrm{S}^{+}$beginning with the second reinstatement test produced strong recovery of responding. Responses at the active lever during presentation of the $\mathrm{S}^{+}$were significantly increased over extinction levels on all $10 \mathrm{~S}^{+}$testing occasions $(p<.01)$ and statistically indistinguishable from cocaine-reinforced responses during the Training Phase (Newman Keuls post-hoc tests after one-way ANOVA: $\left.\mathrm{F}_{17,119}=9.80 ; p<.00001\right)$. The response-reinstating effects of the cocaine $\mathrm{S}^{+}$remained unaltered throughout the nine consecutive sessions, and no differences were observed in the number of responses among tests preceded by vehicle injections (reinstatement sessions 3, 5, 7, and 9) or no injection (sessions 2, 4, 6, 8, 10 and 12) as determined by Newman-Keuls post-hoc analysis. As during the first $\mathrm{S}^{-}$reinstatement test, responding did not increase over extinction levels (Newman-Keuls) during the second $\mathrm{S}^{-}$test on post-extinction day 31 (reinstatement session 11) but recovered fully (Figure 1, reinstatement phase) when the rats were again pre-
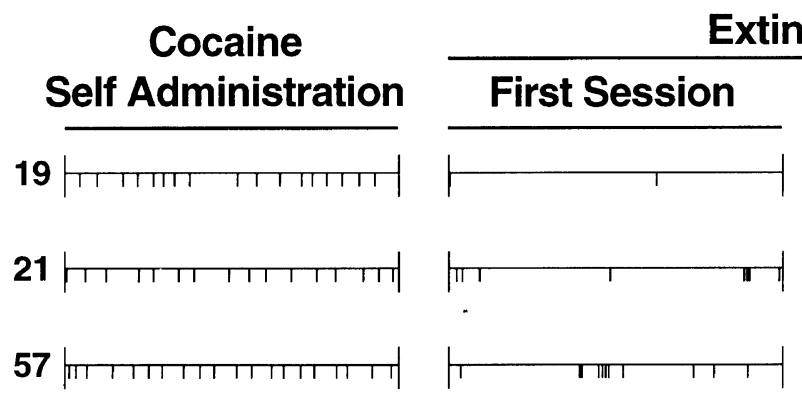

Cue-Induced Reinstatement

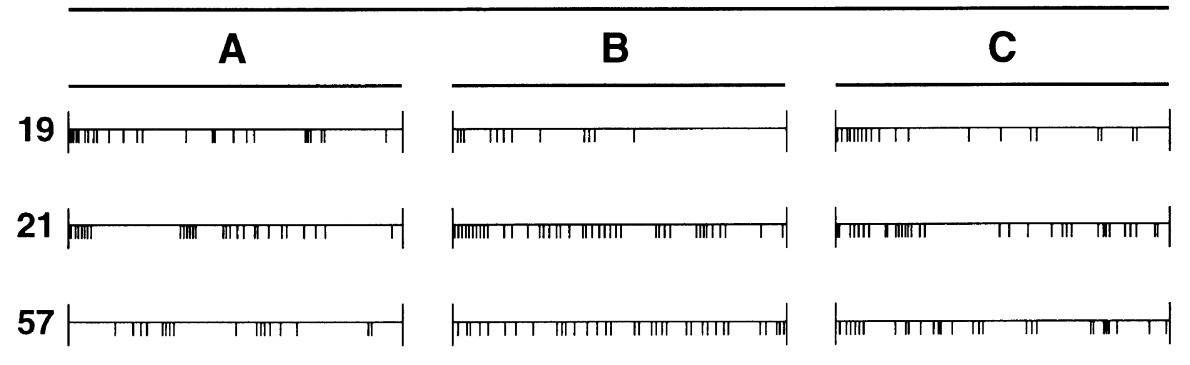

Figure 2. Representative records of three rats illustrating the pattern of responding during the cocaine self-administration, extinction, and reinstatement phases. (All records represent $60 \mathrm{~min}$ sessions). Cocaine Self-Administration: Cocaine-reinforced responding during the last day of the training phase. Extinction: Responses during the first and last session of the extinction phase. Cue-Induced Reinstatement: (Panel A) Responding in the presence of the cocaine $\mathrm{S}^{+}$during the first reinstatement session. (Panels B and C) Response records of the same animals selected arbitrarily at later time points during the 34-day reinstatement testing phase. 
sented with the $\mathrm{S}^{+}$on test day 12 (post-extinction day 34 ). The number of responses at the inactive lever was negligible throughout all reinstatement tests (mean total responses/session: $2.34 \pm 0.31$ ) without differences between $\mathrm{S}^{+}$and $\mathrm{S}^{-}$sessions $\left(\mathrm{F}_{11,77}=1.21 ; \mathrm{NS}\right)$.

Inspection of the response patterns of individual rats revealed that responding in the presence of the $\mathrm{S}^{+}$was sustained throughout all reinstatement sessions, and distinctly different from the pattern of non-reinforced responses during the Extinction Phase. In addition, there was no sign of extinction to the effects of the $\mathrm{S}^{+}$ with repeated testing, and in some animals a pattern of densely distributed but remarkably regular inter-response intervals emerged (Figure 2).

Delayed Reinstatement Test. Presentation of the $\mathrm{S}^{+}$in rats $(\mathrm{N}=4)$ subjected to a total of $17-19$ weeks of abstinence (including the extinction phase) significantly reinstated responding to levels indistinguishable from those during the initial reinstatement phase. Responses in rats $(\mathrm{N}=4)$ presented with the $\mathrm{S}^{-}$remained at extinction levels. ANOVA revealed overall differences in responding across the Self-Administration, Extinction, and Delayed Reinstatement Tests $\left(\mathrm{F}_{2,12}=22.52 ; p<\right.$ .0001). Differences between the behavioral effects of the $\mathrm{S}^{+}$and $\mathrm{S}^{-}$during the Delayed Reinstatement Test were confirmed by a significant interaction between Groups $\left(\mathrm{S}^{+}\right.$vs. $\left.\mathrm{S}^{-}\right)$and Experimental Phases $\left(\mathrm{F}_{2,12}=8.40 ; p<\right.$ $.01)$ followed by simple effects analysis $\left(\mathrm{F}_{1,18}=18.28\right.$; $p<.0001)$. The subgroups of rats assigned to testing with the $\mathrm{S}^{+}$vs. $\mathrm{S}^{-}$did not differ in behavioral performance during the final three days of the Self-Administration $\left(\mathrm{F}_{1,18}=0.84 ; \mathrm{NS}\right)$ and Extinction $\left(\mathrm{F}_{1,18}=0.00 ; \mathrm{NS}\right)$ phases (Figure 3).

\section{Effects of Pharmacological Agents on Cue-Induced Responding}

Rats of the drug treatment group (Group II, $\mathrm{N}=10$ ) reached the training criterion within $8.4 \pm 0.6$ days and did not differ in the number of training days required from Group I $\left(\mathrm{F}_{1,16}=2.90\right.$; NS). Similarly, no differences between Groups I and II were apparent in the number of responses at the active lever during the final three days of the training phase (Figure 1, left panel). This was reflected by a lack of significant differences between "Groups" ( $\mathrm{F}_{1,16}=0.61$; NS) and interactions between "Drug Condition (cocaine vs. saline)" ( $\mathrm{F}_{1,16}=3.20 ; \mathrm{NS}$ ) or "Groups" and "Daily Sessions" ( $\mathrm{F}_{2,23}=1.30$; NS). Rats of Group II made on average $12.27 \pm 1.44$ responses per session during the first three sessions of the extinction phase and reached the extinction criterion within $21.6 \pm 2.0$ sessions. There were no differences between this group and Group I in the number of days to criterion $\left(\mathrm{F}_{1,16}=3.63\right.$; NS) or the number of re-



Figure 3. Long-term persistence of the cue-induced cocaine-seeking behavior in rats confined to their home cages following completion of the reinstatement test series shown in Figure 1 (Group I) and retested after 12-14 weeks of abstinence. Even after this extended abstinence period, the cocaine $\mathrm{S}^{+}$but not $\mathrm{S}^{-}$reinstated cocaine-seeking behavior. For comparison, cocaine self-administration and extinction responses are shown separately for animals tested with the cocaine $\mathrm{S}^{+}\left(\mathrm{S}^{+}\right.$Condition) vs. saline-associated $\mathrm{S}^{-}\left(\mathrm{S}^{-}\right.$ Condition) during the reinstatement tests: (SA) Cocainemaintained responses averaged across the last three days of the Self-Administration Phase. (EXT) Responses averaged across the last three days of the Extinction Phase. ${ }^{* *} p<.01$; different from EXT in $\mathrm{S}^{+}$Condition, and both EXT and $\mathrm{S}^{-}$ performance in $\mathrm{S}^{-}$Condition.

sponses during the last three days of the extinction phase $\left(F_{1,16}=0.67 ; N S\right)$. Responding at the inactive lever was negligible during the Training and Extinction Phases (Figure 1).

The behavioral performance of Group II during both the $\mathrm{S}^{-}$and drug-free $\mathrm{S}^{+}$reinstatement tests was identical to that obtained on the corresponding test days in Group I. Specifically, as in Group I, responding in the presence of the $\mathrm{S}^{-}$did not increase over extinction levels during the first reinstatement test, whereas presentation of the $\mathrm{S}^{+}$in the second reinstatement test produced recovery of responding to levels identical to those during the Self-Administration Training Phase (Figure 1). The $\mathrm{S}^{+}$-induced response reinstatement was confirmed by statistical analysis $[p<.01$; Newman Keuls after overall ANOVA of Extinction vs. $\mathrm{S}^{-}$and $\mathrm{S}^{+}$ responses $\left(\mathrm{F}_{12,96}=12.08 ; p<.00001\right)$; data from one animal in Group II that developed health complications and did not complete all tests were excluded from all statistical analyses, reducing the sample size of Group II to $\mathrm{N}=9$ ]. Responding during $\mathrm{S}^{+}$tests remained stable across the five (pre/post) tests in which these animals received neither drug nor vehicle pretreatments $\left(\mathrm{F}_{4,32}=2.05 ; \mathrm{NS}\right)$. Behavioral performance during $\mathrm{S}^{+}$ tests was identical to that in Group I as indicated by a lack of differences in reinstatement responses between 
groups $\left(\mathrm{F}_{1,15}=0.62 ; \mathrm{NS}\right)$ or interactions $\left(\mathrm{F}_{4,60}=1.73\right.$; NS) between groups and test days (data represent responses during each of the five drug-free $\mathrm{S}^{+}$pre/post tests in Group II vs. the corresponding five $\mathrm{S}^{+}$test sessions in the vehicle-treated rats of Group I. The respective mean \pm SEM responses across the five test days in Groups I and II are shown in Figure 3: "Baseline" C vs. D). In addition, as in Group I, presentation of the $S^{-}$on test day 11 (post-extinction day 31) failed to elicit significant responding, whereas responding recovered fully $(p<.01$; Newman-Keuls tests after one-way ANOVA: $\left.\mathrm{F}_{12,96}=12.08 ; p<.00001\right)$ when these animals were again presented with the $\mathrm{S}^{+}$on test day 12 (post-extinction day 34; data not shown). Responding at the inactive lever was negligible throughout the reinstatement phase without differences among $\mathrm{S}^{+}$and $\mathrm{S}^{-}$sessions $\left(\mathrm{F}_{7,56}=1.40 ; \mathrm{NS}\right)$.

The effects of the pharmacological agents on reinstatement responses in Group II were compared to the number of responses in the vehicle-treated animals of Group I, tested at post-extinction days corresponding to the respective drug test days in Group II. The effects of the pharmacological treatments are shown in Figure 4. None of the agents produced significant changes in responding at the inactive lever $\left(\mathrm{F}_{3,45}=2.69 ; \mathrm{NS}\right)$. In contrast, the drug $\left(\mathrm{F}_{3,45}=6.04 ; p<.002\right)$ but not vehicle $\left(\mathrm{F}_{3,45}=0.23\right.$; NS) treatments exerted significant effects on responding [simple effects after main effect of drug treatments $\left(\mathrm{F}_{3,45}=3.16 ; p<.05\right)$ in overall ANOVA]. Additional simple effects analyses confirmed a significant reduction in $\mathrm{S}^{+}$-induced responding at the active lever by the $\mathrm{D}_{1}$ antagonist $\mathrm{SCH} 39166\left(\mathrm{~F}_{1,15}=9.43 ; p<.01\right)$, the $\mathrm{D}_{2} / \mathrm{D}_{3}$ antagonist nafadotride $\left(\mathrm{F}_{1,15}=6.62 ; p<.05\right)$, and the $\mathrm{D}_{2} / \mathrm{D}_{3}$ agonist PD $128907\left(\mathrm{~F}_{1,15}=9.14 ; p<.01\right)$. No mean change in responses at the active lever was observed after pretreatment with the $D_{1}$ receptor agonist SKF 81297 $\left(\mathrm{F}_{1,15}=0.33 ; \mathrm{NS}\right)$.

Inspection of the data from individual animals revealed that both the $\mathrm{D}_{1}$ antagonist $\mathrm{SCH} 39166$ and the $\mathrm{D}_{2} / \mathrm{D}_{3}$ agonist PD 128907 produced extinction-like response profiles characterized by an initial response burst followed by early termination of responding, similar to that observed during the extinction phase. Treatment with the $D_{1}$ agonist SKF 81297 and the $D_{2} / D_{3}$ antagonist nafadotride was associated with a variable response profile. SKF 81297 produced substantial increases in responding in three animals, intermittent bursts of responding distributed throughout the session in three animals, and complete or near complete suppression of responding in four rats. Nafadotride exerted overall suppressant effects on reinstatement responses, but intermittent response bursts throughout the session were observed in four animals, extinctionlike effects with early termination of responding in three rats, and near complete inhibition of behavior in two animals.

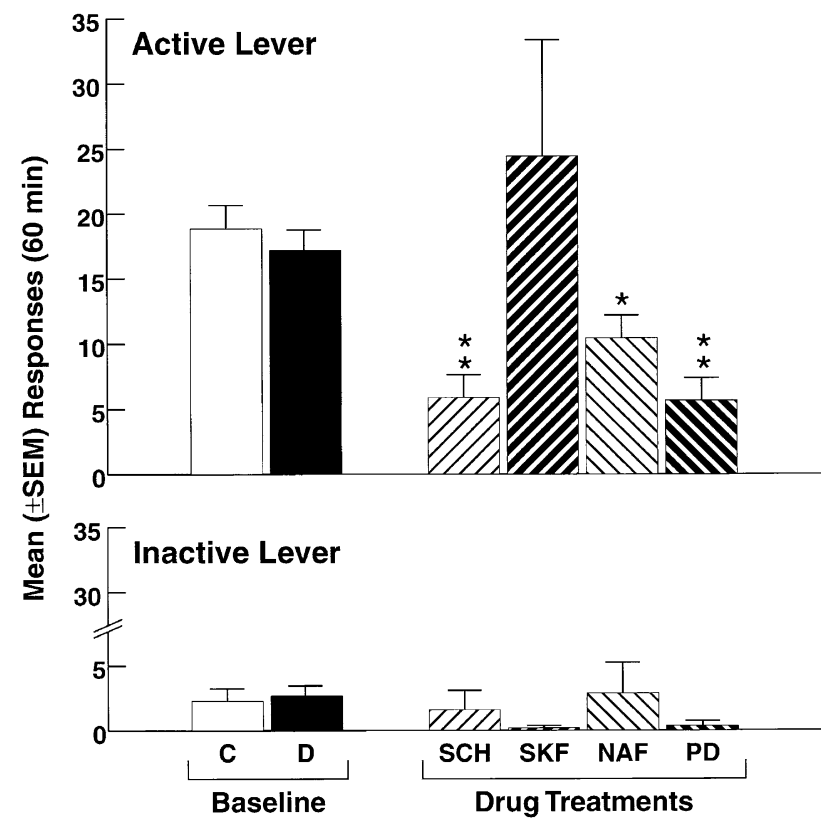

Figure 4. Effects of pharmacological manipulation of DA receptors on $\mathrm{S}^{+}$-induced responding at the previously active (upper panel) and inactive (lower panel) lever. Baseline: Mean \pm SEM responses across the five drug-free $\mathrm{S}^{+}$tests in Group II (D) and the corresponding five $\mathrm{S}^{+}$test sessions (days 4, 10, 16, 22, 28 in Figure 1) in the vehicle-treated rats of Group I (C). Drug Treatments: $\mathrm{S}^{+}$-induced reinstatement responses after pretreatment with the D1 antagonist $\mathrm{SCH}$ 39166 (SCH, $10 \mu \mathrm{g} / \mathrm{kg}$ ); the D1 agonist SKF 81297 (SKF, 1 $\mathrm{mg} / \mathrm{kg}$ ); the D2/3 antagonist nafadotride (NAF, $1 \mathrm{mg} / \mathrm{kg}$ ); and the D2/3 agonist PD 128,907 (PD, $0.3 \mathrm{mg} / \mathrm{kg}$ ). Responding was attenuated by SCH 39166, nafadotride, and PD 128,907, but not by SKF 81297. ${ }^{* *} p<.01,{ }^{*} p<.05$; different from reinstatement performance in vehicle-treated controls (Baseline "C").

\section{DISCUSSION}

The purpose of this investigation was to characterize the persistence of the motivating actions of cocainerelated environmental stimuli with emphasis on the significance of discriminative stimuli for drug availability in the resumption of drug-seeking behavior following extinction and prolonged abstinence. The results confirm that discriminative stimuli associated with the availability and self-administration of cocaine can elicit strong cocaine-seeking behavior in rats as measured by the recovery of extinguished responding at a previously drug-paired lever without further availability of the primary reinforcer. Of particular significance is the finding that the response-reinstating actions of the cocaine $\mathrm{S}^{+}$proved highly resistant to extinction as reflected by the stability of the cue effects throughout the 34-day phase of repeated testing, and by the lack of decreases in the efficacy of the $\mathrm{S}^{+}$in rats that had been 
confined to their home cages for an additional 12-14 weeks. These behavioral effects of the $\mathrm{S}^{+}$cannot be attributed to non-specific arousal or spontaneous recovery since responding at the inactive lever remained negligible and, more importantly, responding in the presence of the $\mathrm{S}^{\mathrm{D}}$ associated with non-reward $\left(\mathrm{S}^{-}\right)$remained at (Figure 1, Day 1; Figure 3) or decreased to (Figure 1, Day 31) extinction levels. These observations indicate that the animals' behavior was controlled selectively by the $\mathrm{S}^{+}$. Finally, the near identical behavioral results obtained during vehicle tests in the drug treatment group confirmed the generality of the resistance to extinction of the cocaine-cue effects.

The results confirm a previous report in which the efficacy of a cocaine $\mathrm{S}^{+}$to elicit drug-seeking behavior remained unaltered over eight days of repeated testing (Weiss et al. 2000) and corroborate related findings that noncontingent presentation of drug-predictive discriminative stimuli can reinstate extinguished approach behavior in an operant runway model of heroin relapse (Ettenberg et al. 1996; McFarland and Ettenberg 1997) as well as responding at a lever previously associated with ethanol or heroin reinforcement (Gracy et al. 2000; Katner et al. 1999; Katner and Weiss 1999). However, the present data extend these earlier findings by demonstrating that the behavioral actions of previously cocaine-predictive discriminative stimuli are remarkably resistant to extinction and endure over prolonged periods of abstinence. Moreover, the undiminished efficacy and selectivity of the cocaine $\mathrm{S}^{+}$to elicit responding at the previously drug-paired lever both with repeated testing and following long-term abstinence suggests that responses conditioned to environmental stimuli acting as discriminative stimuli for drug availability are an important factor in the long-lasting addictive potential of cocaine. Discriminative stimuli signal the availability of a reinforcer under a particular stimulus condition and reinforcement contingency and, thereby, facilitate or set the occasion for behavioral responses directed at obtaining the desired substance or object. The manner in which drug-associated contextual cues attain their motivating effects is likely to involve the occasionsetting nature of such stimuli rather than only classically conditioned responses. Indeed, it has been argued that human drug-seeking behavior may be most appropriately modeled by paradigms in which environmental stimuli that are predictive of drug reinforcement (i.e., discriminative stimuli) facilitate drug-related operant responding (McFarland and Ettenberg 1997). The endurance of the motivating actions of the cocaine $\mathrm{S}^{+}$ supports this hypothesis and suggests that contextual cues that act as discriminative stimuli for drug availability are particularly effective in eliciting and sustaining drug-seeking behavior and, thus, may be a critical environmental factor in compulsive drug-seeking behavior and long-lasting vulnerability to relapse.
In order to fully understand the stimulus conditions that controlled behavior during the reinstatement tests it is necessary, however, to consider that during the self-administration phase the rats were not only exposed noncontingently to the cocaine $\mathrm{S}^{+}$but responses at the active lever also resulted in presentation of a response-contingent cue whose purpose was to signal the 20 -sec post-response inactivation of the cocaine lever to prevent accidental overdosing. Because of the temporal contiguity between cocaine infusions and the "time out (TO)" signal, this stimulus may perhaps have acted as an infusion cue and attained conditioned reinforcing properties that were additive to the occasion-setting effects of the $\mathrm{S}^{+}$. More specifically, the cocaine $\mathrm{S}^{+}$may have primarily facilitated the initiation of responding whereas the response-contingent TO stimulus, acting as a conditioned reinforcer, may have maintained subsequent drug-seeking behavior. The results do not provide direct insight into the relative contribution of the two stimulus categories to the results. However, there is evidence that "time-out" cues that are routinely employed during cocaine self-administration training attain, at best, only modest conditioned reinforcing efficacy. For example, in studies by both Meil and See (1996) and Weissenborn et al. (1995) noncontingent exposure to a TO cue light alone was ineffective in reinstating extinguished responding at a previously cocaine-paired lever. Similarly, response-contingent presentation of a TO cue light maintained conditioned responding only when preceded by a cocaine priming injection (Weissenborn et al. 1995). Consistent with these observations, omission of the TO stimulus in a preliminary examination of interactions between the $\mathrm{S}^{+}$ and TO cue-conducted after completion of the repeated cue exposure phase in rats not assigned to the prolonged abstinence condition-produced only a moderate $35 \%$ decrease in $\mathrm{S}^{+}$-induced responses (data not shown). Conversely, introduction of a cocaine $\mathrm{S}^{+}$increased responding by $300 \%$ over (low) levels of responding maintained by a response-contingent $\mathrm{TO}$ stimulus alone (Weiss 1996). Thus, while conditioned reinforcing effects by the "time-out" stimulus may have enhanced the magnitude of the response reinstatement, available data suggest that drug-seeking behavior under the present contingencies was controlled primarily by the $\mathrm{S}^{+}$.

There are two issues that require consideration for the understanding of possible interactions between the $\mathrm{S}^{+}$and TO cue. First, discriminative stimuli can acquire the ability to "set the occasion" for either reinforcement or non-reinforcement and to modulate responding generated by other conditioned stimuli in a manner that is independent of the association of the occasion setter with the unconditioned stimulus (Holland 1983; Rescorla 1985). For example, nonreinforced presentation of an occasion setter to extinguish associations between 
this cue and an associated unconditioned stimulus does not affect control of responding to a relevant conditioned stimulus by the occasion setter (Bouton and Swartzentruber 1986). It is possible that the training procedure in the present experiment conveyed occasion setting to the cocaine $\mathrm{S}^{+}$that resulted in a "facilitation" of responses to the TO light cue. More importantly, according to this account, the remarkable persistence of non-reinforced responding in the presence of the $\mathrm{S}^{+}$ may have been related to difficulties in extinguishing the occasion-setting property of this discriminative stimulus. A second consideration relevant for possible interactions between the $\mathrm{S}^{+}$and TO cue is that the concurrent presentation of the $\mathrm{S}^{+}$and cocaine-contiguous TO cue during training produced some form of compound stimulus with greater salience and consequently greater efficacy in establishing and maintaining responding. Many classically conditioned responses are greater when elicited by a compound conditioned stimulus relative to responses produced by its component stimuli (for review, see e.g., Baker 1968). Recent studies have established that these effects of compound stimuli extend to cocaine-related conditioned responses. Compound cues involving both classically conditioned (See et al. 1999) and discriminative stimuli (Panlilio et al. 1996) have been shown to enhance cocaine-seeking behavior in animal models of cocaine reinforcement and relapse relative to the effects of the respective individual stimulus components. The preliminary findings that omission of the "time-out" stimulus produced a moderate decrease in $\mathrm{S}^{+}$-induced responses and that introduction of an $\mathrm{S}^{+}$increased responding maintained by a response-contingent TO stimulus alone (Weiss 1996) suggest that compound stimulus effects may have been a factor in the magnitude of the response-reinstatement observed here as well.

While understanding of the precise nature of the stimulus control of behavior under the present contingencies will require further investigation, the results demonstrate that these stimulus conditions elicit strong and remarkably persistent cocaine-seeking behavior. Moreover, as illustrated in Figure 2, exposure to the $\mathrm{S}^{+}$ did not simply elicit a transient behavioral response that extinguished when lever-pressing was not reinforced by cocaine, but produced sustained responding throughout the test sessions. Typical extinction-like response profiles-characterized by repetitive response bursts after the onset of test sessions and eventual cessation of responding-were rarely observed. Importantly as well, throughout the course of the reinstatement test phase, all animals typically initiated responding immediately after the onset of each session in spite of absence of the primary reinforcer during the preceding session (i.e., access to the previously cocainepaired lever under extinction conditions). The endurance of the behavioral effects of the cocaine $\mathrm{S}^{+}$observed here appears analogous to the persistence of conditioned cue reactivity and cue-induced craving in humans (e.g., Childress et al. 1993) that has been implicated as a critical factor in long-lasting relapse risk and high rates of recidivism (e.g., O'Brien et al. 1998). Thus, the procedures employed here may provide a valuable tool for future investigations of behavioral and neurobiological factors underlying conditioned cue reactivity, cue-induced cocaine craving, and relapse.

Exposure to a cocaine-predictive discriminative stimulus was recently shown to significantly increase dopamine efflux in the nucleus accumbens and amygdala of rats as measured by microdialysis (Weiss et al. 2000). This finding suggested that the conditioned behavioral effects of cocaine-related stimuli may depend on activation of dopamine neurotransmission within limbic forebrain regions (Weiss et al. 2000). It was, therefore, important to examine whether the response-reinstating actions of a cocaine $\mathrm{S}^{+}$can be altered by pharmacological manipulation of DA transmission. The approach employed for this purpose was to screen several ligands for the $D_{1}$ and $D_{2 / 3}$ families of receptors, each at a dose that was previously shown to modify cocaine self-administration or other cocaine-related behaviors (Caine et al. 1997; Parsons et al. 1996; Self et al. 1996; Weissenborn et al. 1996). While a single-dose pharmacological testing strategy is inevitably fraught with limitations regarding the interpretation of the data, the overall pattern of results is consistent with the hypothesis that the behavioral effects of cocaine-predictive stimuli are sensitive to pharmacological manipulation of dopamine receptors. In particular, the selective $D_{1}$ antagonist SCH 23390 produced a complete reversal of the effects of the cocaine $\mathrm{S}^{+}$with an extinction-like behavioral profile characterized by initial intermittent response bursts followed by eventual termination of responding. It is unlikely that the suppression of cue-induced responding by $\mathrm{SCH} 23390$ was merely the result of general disruptive effects or impairments in motor performance. Lowdose $\mathrm{D}_{1}$ antagonist treatments alter the direct reinforcing actions of cocaine without interfering with motor performance (Amalric et al. 1993) or food-maintained behavior (Caine and Koob 1994). Consistent with these observations, a selective $\mathrm{D}_{1}$ antagonist ( $\mathrm{SCH}$ 39166) was recently shown to attenuate the euphoric effects of cocaine in humans without inducing sedation or nonspecific anhedonic effects (Romach et al. 1999). More importantly, SCH 23390 selectively and dose-dependently reduced conditioned responding maintained by a cocaine-related conditioned stimulus, while leaving fully intact behavior maintained by a stimulus associated with a food reinforcer (Weissenborn et al. 1996). There is evidence that cocaine-predictive discriminative (Ciccocioppo et al. 1999) and cocaine-paired contextual stimuli (Neisewander et al. 2000) potently induce Fos expression within the basolateral amygdala and ante- 
rior cingulate cortex of rats, and that these effects are reversed by the selective $\mathrm{D}_{1}$ antagonist $\mathrm{SCH} 39166$ (Ciccocioppo et al. 1999). In light of these findings, the reversal of the behavioral effects of a cocaine-predictive discriminative stimulus by a selective $\mathrm{D}_{1}$ antagonist in the present study identifies the $\mathrm{D}_{1}$ receptor as a particularly promising target for the further exploration of the neuropharmacological basis of cue-induced cocaineseeking behavior.

The $\mathrm{D}_{2 / 3}$ antagonist nafadotride also produced a significant mean decrease in cue-induced responding and, as in the case of SCH 23390, this effect was associated with an extinction-like behavioral profile in the majority of the animals. Nafadotride has been shown to increase cocaine self-administration in rats, an effect that has been interpreted as reflective of an attenuation of the reinforcing actions of cocaine (Caine et al. 1997). Consistent with a functional dopamine antagonist action as well, nafadotride reversed autoregulatory decreases in accumbal dopamine release induced by the $\mathrm{D}_{2 / 3}$ agonist 7-OH-DPAT (Parsons et al. 1996). The inhibitory effects on cue-induced responding by both a $D_{1}$ and $\mathrm{D}_{2 / 3}$ receptor antagonist, therefore, complement the finding that cocaine-predictive discriminative stimuli can increase dopamine release in the amygdala and nucleus accumbens (Weiss et al. 2000) and provide further support for the hypothesis that the behavioral effects of such stimuli may involve activation of neurotransmission in these brain regions.

The $\mathrm{D}_{1}$ agonist SKF 81297 produced a variable behavioral profile, attenuating or eliminating cue-induced responding in some animals, while augmenting this behavior in others. In instances where SKF 81297 attenuated the effects of the cocaine $\mathrm{S}^{+}$, the initiation of responding was either substantially delayed or rats failed to respond throughout the session. One explanation for this observation is that SKF 81297 substituted for the pharmacological actions of cocaine in these animals and, thereby, decreased or eliminated cocaine-seeking behavior. This interpretation is consistent with reports that $D_{1}$ agonists can substitute for the reinforcing effects of cocaine in rhesus monkeys (Weed et al. 1993, 1997; Weed and Woolverton 1995) and effectively block drugseeking behavior induced by cocaine priming injections in rats, presumably as a result of their cocaine-like pharmacological action (Self et al. 1996). In rats that showed an augmented behavioral response to the cocaine $\mathrm{S}^{+}$after SKF 81297, responding was vigorous and sustained throughout the session. The most likely explanation for the divergent behavioral profile of SKF 81297 is that the $1.0 \mathrm{mg} / \mathrm{kg}$ dose of this $\mathrm{D}_{1}$ agonist represented a threshold dose that produced cocaine-like priming effects in some animals while substituting for the effects of cocaine in others. Another intriguing possible interpretation for the effects of SKF 81297 comes from recent elec- trophysiological data showing that medium spiny neurons in the nucleus accumbens receiving strong depolarizing glutamatergic input exhibit a strong excitatory response to local microiontophoretic application of SKF 81297 while neurons that receive weak glutamatergic input, not sufficient to produce burst firing, consistently show a $\mathrm{D}_{1}$-mediated decrease in excitability (Cooper and White 1999). These findings were interpreted to suggest that the level of excitatory input received by accumbal medium spiny neurons may be a determining factor in their response to $\mathrm{D}_{1}$ receptor stimulation (Cooper and White 1999). It is known that increasing the excitability of accumbal neurons by enhancing glutamatergic tone elicits cocaine-seeking behavior (Cornish et al. 1999). Thus, individual differences in the level of glutamatergic excitatory drive may have been responsible for the capability of SKF 81297 to augment reinstatement in some rats and to reduce this behavior in others.

The $\mathrm{D}_{2 / 3}$ agonist PD 128907 significantly suppressed the recovery of responding in the presence of the cocaine $\mathrm{S}^{+}$. The $0.3 \mathrm{mg} / \mathrm{kg}$ dose of PD 128907 corresponds to a dose previously found to increase the reinforcing actions of cocaine in self-administering rats (Caine et al. 1997). Thus, one interpretation to account for the effects of PD 128907 is that this compound substituted for the effects of cocaine, thereby decreasing the motivating actions of the cocaine cue.

Considering the results of the pharmacological tests, and in particular those obtained with the two receptor agonist compounds, it is clear that an understanding of the role of dopamine receptors as well as the possibility of a preferential mediation of this behavior by particular receptor types will require more systematic investigation in the future. Nonetheless, the attenuation of cueinduced cocaine-seeking behavior by SCH 23390 and nafadotride is consistent with the finding that cocaineassociated environmental stimuli increase extracellular dopamine levels in limbic brain regions (Weiss et al. 2000). Moreover, these data complement and extend prior evidence that has implicated $\mathrm{D}_{1}$ (Ciccocioppo et al. 1999; Spealman et al. 1999; Weissenborn et al. 1996) and $D_{2 / 3}$ (Pilla et al. 1999) receptors in the mediation of the conditioned effects of cocaine-related environmental stimuli.

In conclusion, the results show that cocaine-seeking behavior elicited by drug-related discriminative stimuli in rats is highly resistant to extinction. The enduring responsiveness to these stimuli may involve learned or drug-induced changes in dopaminergic function, necessary for the expression of cocaine-seeking behavior induced by cocaine-predictive environmental stimuli. Further research will be essential to more precisely identify the stimulus and learning conditions, as well as dopamine receptor types mediating the motivating effects of cocaine-related environmental stimuli. 


\section{ACKNOWLEDGMENTS}

This work was supported by grant DA07348 from the National Institute on Drug Abuse. This is publication number 12998-NP from The Scripps Research Institute. The authors thank Kia Pederson for assistance with the pharmacological tests and Mike Arends for help with the preparation of the manuscript.

\section{REFERENCES}

Amalric M, Berhow M, Polis I, Koob GF (1993): Selective effects of low dose D2 dopaminergic receptor antagonism in a reaction time task in rats. Neuropsychopharmacol 8:195-200

Baker TW (1968): Properties of compound conditioned stimuli and their components. Psychol Bull 70:611-625

Bouton ME, Swartzentruber D (1986): Analysis of the associative and occasion-setting properties of contexts participating in a Pavlovian discrimination. Journal of Experimental Psychology: Animal Behavior Processes 12:333-350

Breiter HC, Gollub RL, Weisskoff RM, Kennedy DN, Makris N, Berke JD, Goodman JM, Kantor HL, Gastfriend DR, Riorden JP, Matthew RT, Rosen BR, Hyman SE (1997): Acute effects of cocaine on human brain activity and emotion. Neuron 19:591-611

Caine SB, Koob GF (1994): Effects of D-1 and D-2 antagonists on cocaine self-administration under different schedules of reinforcement in the rat. J Pharmacol Exp Ther 270:209-218

Caine SB, Koob GF, Parsons LH, Everitt BJ, Schwartz JC, Sokoloff P (1997): D3 receptor test in vitro predicts decreased cocaine self-administration in rats. Neuroreport 8:2373-2377

Caine SB, Lintz R, Koob GF (1993): Intravenous drug selfadministration techniques in animals. In Saghal A (ed), Behavioral Neuroscience: A Practical Approach, Vol 2. Oxford, University Press, pp 117-143

Carroll KM, Rounsaville BJ, Keller DS (1991): Relapse prevention strategies for the treatment of cocaine abuse. Am J Drug Alcohol Abuse 17:249-265

Childress AR, Ehrman RN, McLellan AT, O’Brien CP (1988): Conditioned craving and arousal in cocaine addiction: A preliminary report, NIDA Research Monograph 81 . Washington, DC, US Government Printing Office, pp 74-80

Childress AR, Hole AV, Ehrman RN, Robbins SJ, McLellan AT, O'Brien CP (1993): Cue reactivity and cue reactivity interventions in drug dependence. NIDA Res Monogr 137:73-95

Childress AR, Mozley PD, McElgin W, Fitzgerald J, Reivich M, O'Brien CP (1999): Limbic activation during cueinduced cocaine craving. Am J Psychiatry 156:11-18

Ciccocioppo R, Sanna PP, Weiss F (1999): Environmental cues potently reinstate cocaine-seeking behavior and induced c-fos after 3-4 months of abstinence. Soc Neurosci Abstr 25

Cooper DC, White FJ (1999): Dopamine D1 receptors signaling in the nucleus accumbens: Relationship to cocaineseeking behavior. Soc Neurosci Abstr 25:1072
Cornish JL, Duffy P, Kalivas PW (1999): A role for nucleus accumbens glutamate transmission in the relapse to cocaine-seeking behavior. Neuroscience 93:1359-1367

DeLong W (1994): Relapse Prevention: an emerging technology for promoting long-term drug abstinence. Int J Addict 29:681-705

deWit H, Stewart J (1981): Reinstatement of cocaine-reinforced responding in the rat. Psychopharmacology 75:134-143

Ehrman RN, Robbins SJ, Childress AR, O'Brien CP (1992): Conditioned responses to cocaine-related stimuli in cocaine abuse patients. Psychopharmacology 107:523-529

Ettenberg A, MacConell LA, Geist TD (1996): Effects of haloperidol in a response-reinstatement model of heroin relapse. Psychopharmacology (Berl) 124:205-210

Fuchs RA, Tran-Nguyen LT, Specio SE, Groff RS, Neisewander JL (1998): Predictive validity of the extinction/reinstatement model of drug craving. Psychopharmacology (Berl) 135:151-160

Garavan H, Bloom AS, Sperry LL, et al (1998): Limbic and cortical activation specific to cue-induced cocaine craving. National Institute on Drug Abuse Research Monograph Series 179:108

Gracy KN, Dankiewicz LA, Weiss F, Koob GF (2000): Heroin-specific cues reinstate heroin-seeking behavior in rats after prolonged extinction. Pharmacol Biochem Behav 65:489-494

Grant S, London ED, Newlin DB, et al (1996): Activation of memory circuits during cue-elicited cocaine craving. Proc Natl Acad Sci U S A 93:12040-12045

Holland PC (1983): Occasion setting in Pavlovian feature positive discriminations. In Commons ML, Herrnstein RJ, Wagner AR (eds), Quantitative Analyses of Behavior, Vol 4. New York, Ballinger, pp 183-206

Katner SN, Magalong JG, Weiss F (1999): Reinstatement of alcohol-seeking behavior by drug-associated discriminative stimuli after prolonged extinction in the rat. Neuropsychopharmacology 20:471-479

Katner SN, Weiss F (1999): Ethanol-associated olfactory stimuli reinstate ethanol-seeking behavior after extinction and modify extracellular dopamine levels in the nucleus accumbens. Alcohol Clin Exp Res 23:1751-1760

Kilgus MD, Pumariega AJ (1994): Experimental manipulation of cocaine craving by videotaped environmental cues. Southern Med J 87:1138-1140

Leshner AI (1997): Addiction is a brain disease, and it matters. Science $278: 45-47$

McFarland K, Ettenberg A (1997): Reinstatement of drugseeking behavior produced by heroin-predictive environmental stimuli. Psychopharmacology (Berl) 131:86-92

Meil WM, See RE (1996): Conditioned cued recovery of responding following prolonged withdrawal from selfadministered cocaine in rats: an animal model of relapse. Behav Pharmacol 7:754-763

Miller NS, Gold MS (1994): Dissociation of “conscious desire" (craving) from and relapse in alcohol and cocaine dependence. Ann Clin Psychiatry 6:99-106 
Neisewander JL, Baker DA, Fuchs RA, Tran-Nguyen LT, Palmer A, Marshall JF (2000): Fos protein expression and cocaine-seeking behavior in rats after exposure to a cocaine self-administration environment. J Neurosci 20:798-805

O'Brien CP, Childress AR, Ehrman R, Robbins SJ (1998): Conditioning factors in drug abuse: Can they explain compulsion? J Psychopharmacol 12:15-22

O'Brien CP, McLellan AT (1996): Myths about the treatment of addiction. Lancet 347:237-240

Panlilio LV, Weiss SJ, Schindler CW (1996): Cocaine selfadministration increased by compounding discriminative stimuli. Psychopharmacology (Berl) 125:202-208

Parsons LH, Caine SB, Sokoloff P, Schwartz JC, Koob GF, Weiss F (1996): Neurochemical evidence that postsynaptic nucleus accumbens D3 receptor stimulation enhances cocaine reinforcement. J Neurochem 67:1078-1089

Pilla M, Perachon S, Sautel F, Garrido F, Mann A, Wermuth CG, Schwartz J-C, Everitt BJ, Sokoloff P (1999): Selective inhibition of cocaine-seeking behaviour by a partial dopamine D3 receptor agonist. Nature 400:371-375

Rescorla RA (1985): Conditioned Inhibition and facilitation. In Miller RR, Spear NE (eds), Information Processing in Animals: Conditioned Inhibition. Hillsdale, NJ, Erlbaum, pp 299-326

Robbins SJ, Ehrman RN, Childress AR, O'Brien CP (1997): Relationships among physiological and self-report responses produced by cocaine-related cues. Addict Behav 22:157-167

Romach MK, Glue P, Kampman K, Kaplan HL, Somer GR, Poole S, Clarke L, Coffin V, Cornish J, O’Brien CP, Sellers EM (1999): Attenuation of the euphoric effects of cocaine by the dopamine D1/D5 antagonist ecopipam (SCH 39166). Arch Gen Psychiatry 56:1101-1106

Satel SL, Krystal JH, Delgado PL, Kosten TR, Charney DS (1995): Tryptophan depletion and attenuation of cueinduced craving for cocaine. Am J Psychiatry 152:778-783

See RE, Grimm JW, Kruzich PJ, Rustay N (1999): The importance of a compound stimulus in conditioned drugseeking behavior following one week of extinction from self-administered cocaine in rats. Drug Alcohol Depend 57:41-49
Self DW, Barnhart WJ, Lehrman DA, Nestler EJ (1996): Opposite modulation of cocaine-seeking behavior by D1- and D2-like dopamine receptor agonists. Science 271:1586-1589

Spealman RD, Barrett-Larimore RL, Rowlett JK, Platt DM, Khroyan TV (1999): Pharmacological and environmental determinants of relapse to cocaine-seeking behavior. Pharmacol Biochem Behav 64:327-336

Tiffany ST, Carter BL (1998): Is craving the source of compulsive drug use? J Psychopharmacol 12:23-30

Wallace BC (1989): Psychological and environmental determinants of relapse in crack cocaine smokers. J Subst Abuse Treat 6:95-106

Weed MR, Paul IA, Dwoskin LP, Moore SE, Woolverton WL (1997): The relationship between reinforcing effects and in vitro effects of D1 agonists in monkeys. J Pharmacol Exp Ther 283:29-38

Weed MR, Vanover KE, Woolverton WL (1993): Reinforcing effect of the D1 dopamine agonist SKF 81297 in rhesus monkeys. Psychopharmacology 113:51-52

Weed MR, Woolverton WL (1995): The reinforcing effects of dopamine D1 receptor agonists in rhesus monkeys. J Pharmacol Exp Ther 275:1367-1374

Weiss F (1996): Initiation and maintenance of cocaine-seeking by drug-related stimuli in rats. Behav Pharmacol 7 (Suppl 1):119

Weiss F, Maldonado-Vlaar CS, Parsons LH, Kerr TM, Smith DL, Ben-Shahar O (2000): Control of cocaine-seeking behavior by drug-associated stimuli in rats: Effects on recovery of extinguished operant responding and extracellular dopamine levels in amygdala and nucleus accumbens. Proc Natl Acad Sci USA 97:4321-4326

Weissenborn R, Deroche V, Koob GF, Weiss F (1996): Effects of dopamine agonists and antagonists on cocaineinduced operant responding for a cocaine-associated stimulus. Psychopharmacology 126:311-322

Weissenborn R, Yackey M, Koob GF, Weiss F (1995): Measures of cocaine-seeking behavior using a multiple schedule of food and drug self-administration in rats. Drug Alcohol Dep 38:237-246 